\title{
Correction to: Outcomes Following Percutaneous Microwave and Cryoablation of Lung Metastases from Adenoid Cystic Carcinoma of the Head and Neck: A Bi-Institutional Retrospective Cohort Study
}

Konstantin S. Leppelmann, Cand. Med. ${ }^{1,4}$, Vincent M. Levesque, MA ${ }^{2}$, Alexander C. Bunck, $\mathrm{MD}^{4}$, Alexis M. Cahalane, MD ${ }^{1,5}$, Michael Lanuti, $\mathrm{MD}^{3,5}$, Stuart G. Silverman, MD ${ }^{2,5}$, Paul B. Shyn, MD $^{2,5}$, and Florian J. Fintelmann, MD ${ }^{1,5}$

${ }^{1}$ Department of Radiology, Massachusetts General Hospital, Boston, MA; ${ }^{2}$ Department of Radiology, Brigham and Women's Hospital, Boston, MA; ${ }^{3}$ Department of Surgery, Massachusetts General Hospital, Boston, MA; ${ }^{4}$ Department of Diagnostic and Interventional Radiology, University of Cologne, Faculty of Medicine and University Hospital Cologne, Cologne, Germany; ${ }^{5}$ Harvard Medical School, Boston, MA

\section{CORRECTION TO:}

ANN SURG ONCOL (2021) 28:5829-5839

HTTPS://DOI.ORG/10.1245/S10434-021-09714-4

In the original online version of this article, the wrong percentage of 57.2 was indicated for minor adverse events $(\mathrm{CTCAE} \leq 2)$. The correct percentage is 63.2 .
The original article was corrected.

Publisher's Note Springer Nature remains neutral with regard to jurisdictional claims in published maps and institutional affiliations.

The original article can be found online at https://doi.org/10.1245/ s10434-021-09714-4.

(C) Society of Surgical Oncology 2022

Published Online: 17 Febraury 2022

F. J. Fintelmann, MD

e-mail: fintelmann@mgh.harvard.edu 